\title{
Microstructure and mechanical properties of VT25U/TiB composite prepared in situ by casting and subjected to hot forging
}

\author{
R. A. Gaisin, V.M. Imayev ${ }^{\dagger}$, R. M. Imayev \\ †vimayev@mail.ru
}

Institute for Metals Superplasticity Problems of RAS, 39 Khalturina st., 450001, Ufa, Russia

\begin{abstract}
The work was devoted to study of microstructure and mechanical properties of discontinuously reinforced composite materials based on $\mathrm{Ti} / \mathrm{TiB}$ fabricated in situ using common casting. A two-phase titanium alloy VT25U was taken as a matrix material. The boron addition in an amount of $1.5 \mathrm{wt} . \%$ corresponding to $8 \mathrm{vol} . \% \mathrm{TiB}$ was found optimal. To obtain axially aligned TiB-whiskers and the most creep resistant matrix condition, isothermal two-directional hot forging leading to drawing of the workpiece along third direction followed by annealing in the $\beta$ and $\alpha+\beta$ temperature range was performed. The mechanical properties of the novel VT25U/TiB composite were studied in tension parallel to the predominant orientation of the TiBwhiskers. Along with tensile tests, creep tests were carried out and the obtained properties were compared with those of the matrix alloy subjected to near the same forging and heat treatment. The composite material demonstrated appreciably higher (by $22-50 \%$ ) strength and creep resistance at $T=550-600^{\circ} \mathrm{C}$ in comparison with those of the matrix alloy while retaining acceptable ductility $\left(\delta=3 \%\right.$ at room temperature). The density normalized strength of $\mathrm{VT} 25 \mathrm{U} / \mathrm{TiB}$ at $T=500-700^{\circ} \mathrm{C}$ was higher than that of both the matrix VT25U alloy and all conventional titanium alloys with the operating temperature of $T=500-600^{\circ} \mathrm{C}$. Microstructural examination showed high adhesion strength of interfacial boundaries between the matrix and the $\mathrm{TiB}$-whiskers, which is retained up to $T=700^{\circ} \mathrm{C}$ that correlates with the mechanical properties. Fracture surface observations suggest that the main failure mechanism of the VT25U/TiB composite is fracture of TiB-whiskers followed by ductile failure of the matrix.
\end{abstract}

Keywords: titanium alloys, discontinuously reinforced composites, isothermal forging, microstructure, mechanical properties.

\section{Микроструктура и механические свойства композита ВТ25У/TiB, полученного in situ с помощью литья и подвергнутого горячей ковке}

\author{
Гайсин Р. А., Имаев В. М. ${ }^{\dagger}$, Имаев Р. М. \\ Институт проблем сверхпластичности металлов РАН, ул. Халтурина 39, 450001, Уфа, Россия
}

Работа посвящена исследованию микроструктуры и механических свойств коротковолокнистого композиционного материала на основе Ti/TiB, приготовленного in situ с использованием обычного литья. В качестве матрицы был использован двухфазный титановый сплав ВТ25У, к которому добавляли бор в количестве 1,5 вес.\%, признанном оптимальным, что соответствовало 8 об.\% ТіВ-волокон. Для получения преимущественной ориентации боридов и наиболее жаропрочного состояния матрицы применяли горячую изотермическую ковку в двух направлениях с постепенным вытягиванием деформируемой заготовки вдоль третьего направления с последующим отжигом в $\beta$ и $(\alpha+\beta)$-фазовой области. Для нового композиционного материала ВТ25У /ТiВ вдоль преимущественной ориентации TiB-волокон были выполнены механические испытания на растяжение, а также испытания на ползучесть. Для сравнения аналогичные испытания были выполнены и для матричного сплава после подобной деформационно-термической обработки. Композиционный материал показал повышенные (на 22 - 50\%) прочностные свойства и существенно более высокое сопротивление ползучести при $T=550-600^{\circ} \mathrm{C}$ по сравнению с матричным сплавом при сохранении приемлемой пластичности ( $\delta=3 \%$ при комнатной температуре). По удельной прочности при $T=500-700^{\circ} \mathrm{C}$ композит ВТ25У/ТiВ превосходит не только ВТ25У, но и все традиционные титановые сплавы с рабочей температурой $T=500-600^{\circ} \mathrm{C}$. Микроструктурные исследования свидетельствуют о сохранении высокой адгезионной прочности границ между матрицей и ТiB-волокнами с повышением температуры испытания до $T=700^{\circ} \mathrm{C}$, что коррелирует с полученными механическими свойствами. Изучение поверхности разрушения показало, что разрушение композита ВТ25У/TiB начинается с ТіВ-волокон с последующим вязким разрушением матрицы.

Ключевые слова: титановые сплавы, коротковолокнистые композиты, изотермическая ковка, микроструктура, механические свойства. 


\section{1. Введение}

Для повышения физико-механических свойств и расширения области применения титановых сплавов стремятся повысить их жаропрочность и прочность, для чего в последние годы используют необычные легирующие элементы, а также разрабатывают металломатричные композиционные материалы (КМ) на основе титановых сплавов путем армирования их частицами и/или волокнами различных соединений $[1-4]$. КМ на основе титана и его сплавов упрочняют волокнами и частицами соединений $\mathrm{TiB}_{2}, \mathrm{~B}_{4} \mathrm{C}, \mathrm{TiN}, \mathrm{SiC}, \mathrm{TiB}, \mathrm{TiC}, \mathrm{Al}_{2} \mathrm{O}_{3}$ и др.

Сравнение свойств различных керамических соединений и титана показывает, что моноборид титана (ТiB) обладает наиболее подходящим балансом свойств: высокой химической стабильностью, высокой прочностью и модулем упругости, близким к титану коэффициентом термического расширения при низкой растворимости бора в титане (Табл. 1) [1-3]. Важным преимуществом моноборида титана является также его возможность образования in situ при изготовлении Ti/TiB композита с помощью порошковых технологий или обычного литья, при этом межфазная граница между ТіВ и титановой матрицей, будучи когерентной, характеризуется высокой адгезионной прочностью $[5,6]$.

Основным способом получения КМ на основе $\mathrm{Ti} / \mathrm{TiB}$ является компактирование и спекание порошков титановой матрицы и диборида титана. При этом диборид титана вступает в реакцию с титаном, образуя моноборид титана в виде коротких волокон. Недостатками использования порошковой технологии являются относительно высокая стоимость, остаточная пористость в компактированных образцах, сложность контроля химической чистоты материала в процессе изготовления и, в итоге, низкая пластичность и недостаточная вязкость разрушения. Альтернативным способом изготовления КМ на основе $\mathrm{Ti} / \mathrm{TiB}$ является обычное литье. Такой способ изготовления композитов существенно упрощает их производство и снижает себестоимость. В последние годы для различных КМ на основе $\mathrm{Ti} / \mathrm{TiB}\left(\mathrm{Ti} / \mathrm{TiB}+\mathrm{TiC}, \mathrm{Ti} / \mathrm{TiB}+\mathrm{Al}_{2} \mathrm{O}_{3}\right.$ и др.), изготовленных литьем, было показано, что они обладают повышенной прочностью, жесткостью, повышенным сопротивлением ползучести и усталостному разрушению при пониженной пластичности и вязкости разрушения [6 - 16]. Важными и недоисследованными в случае КМ, изготовленных литьем, остаются следующие вопросы:
- оптимальное содержание вводимого бора, исключающего образование грубых первичных боридов (характерных для заэвтектических составов $[7,8]$ ), ухудшающих механические свойства, которое зависит от выбора матрицы;

- разработка эффективного способа переориентации ТiB-волокон, который бы сохранял высокое соотношение длины и поперечного размера волокон;

- адгезионная прочность границ матрица/TiB при повышенных температурах;

- оптимизация микроструктуры матрицы.

В настоящей работе изучали неисследованный ранее КМ, изготовленный литьем, на основе жаропрочного двухфазного титанового сплава ВТ25У, взятого в качестве матричного материала. Количество вводимого бора (объемной доли ТіВ-волокон) оптимизировали экспериментально, основываясь на бинарной диаграмме Ті-В и ранее выполненных работах [7 - 9, 13], с тем, чтобы исключить образование грубых первичных боридов. КМ с преимущественно ориентированными ТіВ-волокнами, полученными с помощью горячей изотермической ковки в двух направлениях, испытывали на растяжение и сопротивление ползучести. Механические свойства ВТ25У/ТiВ были сравнены со свойствами матричного сплава. Особое внимание было уделено анализу разрушения КМ, в частности, процессам нарушения сплошности на границах между матрицей и ТiВ-волокнами.

\section{2. Материалы и методики эксперимента}

В качестве матричного материала был выбран сплав BT25У. Состав матричного сплава, уточненный с помощью EDX анализа, приведен в Табл. 2.

При изготовлении композиционных материалов ВТ25У/ТiВ в сплав добавляли бор в виде аморфного порошка (чистотой $\geq 99,5 \%$ ) в количестве 1,5 и 1,7 вес.\%, а также дополнительно вводили титан (чистотой $\geq 99,74 \%$ ), чтобы компенсировать его дефицит из-за образования моноборида титана. Композиты выплавляли в виде 100-граммовых слитков с помощью аргонно-дуговой плавки на лабораторной литейной установке. Температуру полиморфного превращения $\left(T_{n n}\right)$ изучаемых материалов определяли перед проведением деформационно-термической обработки с помощью дифференциально-сканирующей калориметрии на установке Netzsch STA 449F1 Jupiter. Она составила для ВТ25У и ВT25У-1,5B

Табл. 1. Свойства ТiВ (структура В27) и других керамических соединений [1 - 3].

Table 1. Properties of TiB (lattice B27) and other ceramic compounds [1-3].

\begin{tabular}{|c|c|c|c|c|c|c|c|c|c|c|}
\hline $\begin{array}{c}\text { Свойства } \\
\text { Сharacteristics }\end{array}$ & $\mathrm{Ti}$ & $\mathrm{TiB}$ & $\mathrm{TiC}$ & $\mathrm{TiN}$ & $\mathrm{TiB}_{2}$ & $\mathrm{SiC}$ & $\mathrm{Si}_{3} \mathrm{~N}_{4}$ & $\mathrm{~B}_{4} \mathrm{C}$ & $\mathrm{Al}_{2} \mathrm{O}_{3}$ & $\mathrm{Ti}_{5} \mathrm{Si}_{3}$ \\
\hline $\begin{array}{c}\text { Плотность, } \mathrm{\Gamma} / \mathrm{cm}^{3} \\
\text { Density, g/cm }\end{array}$ & 4,57 & 4,56 & 4,92 & 5,43 & 4,52 & 3,21 & 3,29 & 2,52 & 4,1 & 4,26 \\
\hline $\begin{array}{c}\text { Модуль Юнга, ГПа } \\
\text { Еlasticity modulus, GPa }\end{array}$ & 110 & 550 & 460 & 390 & 529 & 420 & 320 & 449 & 350 & 156 \\
\hline $\begin{array}{c}\text { Предел прочности, ГПа } \\
\text { Ultimate tensile strength, GРа }\end{array}$ & 0,22 & 8 & 3,55 & - & - & 3,45 & $<1$ & - & - & - \\
\hline $\begin{array}{c}\text { Коэффициент термического расширения } \\
\text { при } 20^{\circ} \mathrm{C}\left(\times 10^{-6}\right), \mathrm{K}^{-1} \\
\text { Thermal ехрапsion соеfficient at } 20^{\circ} \mathrm{C}\left(\times 10^{-6}\right), \mathrm{K}^{-1}\end{array}$ & 8,8 & 8,6 & 7,4 & 9,35 & 6,4 & 4,3 & 3,2 & 4,5 & 8,1 & 7,3 \\
\hline
\end{tabular}


$T_{n n} \approx 1010^{\circ} \mathrm{C}$, т.е. введение бора заметно не повлияло на температуру полиморфного превращения.

Для достижения преимущественной ориентации TiB-волокон использовали изотермическую ковку в двух направлениях при $T=1050^{\circ} \mathrm{C}$ так, что заготовка в процессе деформации вытягивалась в третьем направлении. Деформационную обработку осуществляли на гидравлическом прессе, оснащенном изотермическим штамповым блоком, со скоростью $\varepsilon^{\prime}=10^{-2}-10^{-3} \mathrm{c}^{-1}$ на суммарную степень деформации $\varepsilon \approx 3$. Таким же образом деформировали литые заготовки сплава ВТ25У. Деформированные заготовки сплава и композита подвергали термической обработке (Табл. 3).

Микроструктурные исследования проводили с помощью растрового электронного микроскопа Mira-3 Tescan в режиме вторичных (SE) или обратно-рассеянных (BSE) электронов. По электронно-микроскопическим снимкам оценивали объемную долю волокон моноборида титана, размеры исходных $\beta$ зерен и $\alpha / \beta$ колоний, толщину пластин. Энергодисперсионная приставка микроскопа была использована при проведении энергодисперсионного микрорентгеноспектрального (EDX) анализа. Перед изучением микроструктуры поверхность образцов подвергали механической и электролитической полировке, а также легкому травлению.

Механические испытания на растяжение образцов ВТ25У/TiB и ВТ25У проводили при $T=20-600^{\circ} \mathrm{C}$. Для этого из материалов, полученных после деформационной и термической обработки, искровым способом вырезали плоские образцы на растяжение с размерами рабочей части $10 \times 3,5 \times 1,5$ мм $^{3}$. Образцы механически шлифовали и полировали перед испытаниями, на каждую точку испытывали не менее 3 образцов. Испытания на ползучесть были выполнены при $T=500-600^{\circ} \mathrm{C}$ по 2 образца на каждую точку. Для этого использовали плоские образцы с размерами рабочей части $17 \times 3 \times 3$ мм $^{3}$, которые испытывали в течение 50 часов. Испытания были выполнены на воздухе.

\section{3. Результаты и обсуждение}

\section{1. Исходное состояние}

На рис. 1 представлена микроструктура сплава ВТ25У и композиционных материалов ВТ25У/ТiВ в исходном литом состоянии. В литом состоянии сплав имеет обычную крупнозернистую $\alpha+\beta$ структуру корзиночного плетения, размер исходных $\beta$ зерен составляет $D_{\beta}=2000 \pm 500$ мкм, толщина пластин $-b_{\alpha}=0,3$ мкм. При введении бора образуются короткие волокна моноборида титана. Видно, что добавление 1,7 вес. \% бора приводит к образованию грубых первичных боридов, в то время как при добавлении 1,5 вес. \% бора этого не наблюдается, а распределение боридов оказывается более однородным. В ВТ25У-1,5В ТіВ-волокна ориентированы хаотично, их размер составляет 0,5 - 5 × 10 - 200 мкм, объемная доля - около 8\%. Присутствие боридов приводит к измельчению матричной структуры - размера исходных $\beta$ зерен и $\alpha / \beta$ колоний. Для последующего изучения механических свойств был выбран композиционный материал ВТ25У-1,5В.

\section{2. Состояние материалов после деформаци- онной и термической обработки}

На рис. 2 представлена микроструктура сплава и композита после деформационной и термической обработки. В сплаве ВТ25У была получена дуплексная структура, состоящая из первичных $\alpha$-зерен и $\beta$ превращенной структуры, со средним размером зерен/колоний $d \approx 10$ мкм. В композите была получена полностью $\beta$ превращенная пластинчатая структура с размером $\alpha / \beta$ колоний в диапазоне $d=10-60$ мкм и с ТіВ-волокнами, имеющими преимущественную ориентировку, при этом соотношение длины и поперечного размера волокон после деформации заметно не изменилось.

Табл. 2. Химический состав исследуемых материалов.

Table 2. The material compositions under study.

\begin{tabular}{|c|c|c|c|c|c|c|c|c|}
\hline \multirow{2}{*}{$\begin{array}{c}\text { Обозначение материала } \\
\text { Material designation }\end{array}$} & \multicolumn{7}{|c|}{$\begin{array}{c}\text { Содержание элементов, вес. \% } \\
\text { Composition, wt. \% }\end{array}$} \\
\cline { 2 - 12 } & $\mathrm{Ti}$ & $\mathrm{Al}$ & $\mathrm{Sn}$ & $\mathrm{Zr}$ & $\mathrm{Mo}$ & $\mathrm{W}$ & $\mathrm{Si}$ & $\mathrm{B}$ \\
\hline $\begin{array}{c}\text { BT25y } \\
\text { VT25U }\end{array}$ & $\begin{array}{c}\text { ocн. } \\
\text { bal. }\end{array}$ & 6.8 & 2,1 & 2 & 3,5 & 0,8 & 0,2 & - \\
\hline $\begin{array}{c}\text { BT25Y-1,5B } \\
\text { VT25U-1,5B }\end{array}$ & $\begin{array}{c}\text { ocн. } \\
\text { bal. }\end{array}$ & 6.8 & 2,1 & 2 & 3,5 & 0,8 & 0,2 & $1,5 / 1,7$ \\
\hline
\end{tabular}

Табл. 3. Термическая обработка деформированных заготовок.

Table 3. Heat treatment of the forged workpieces.

\begin{tabular}{|c|c|}
\hline $\begin{array}{c}\text { Материал } \\
\text { Material }\end{array}$ & Условия термической обработки \\
Heat treatment conditions \\
\hline ВT25У
\end{tabular}

${ }^{\star}$ Each annealing was followed by air cooling.

* После каждой операции отжига осуществляли охлаждение на воздухе. 


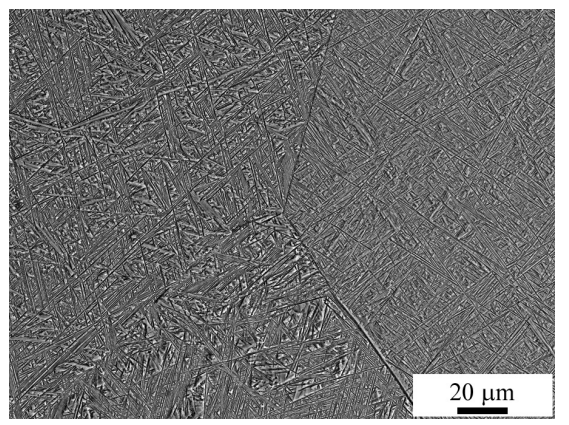

a

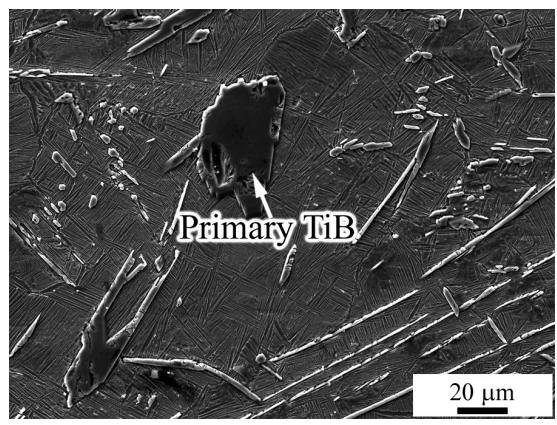

b

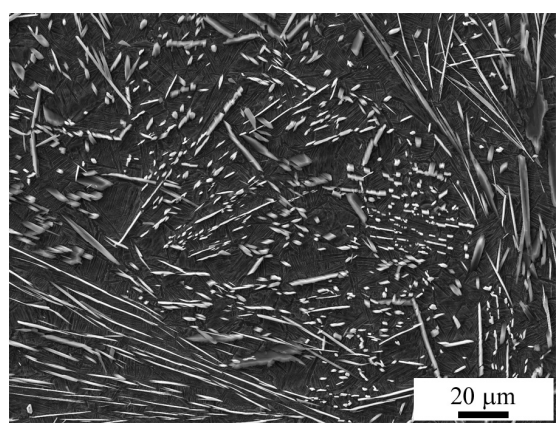

$\mathrm{C}$

Рис. 1. Микроструктура исходных материалов в литом состоянии: (а) ВТ25У, (b) ВТ25У-1,7B, (c) ВТ25У-1,5В (РЭМ, SE). Стрелка указывает на грубый первичный борид.

Fig. 1. Microstructures of initial materials in as-cast conditions: (a) VT25U, (b) VT25U-1,7B, (c) VT25U-1,5B (SEM, SE). The arrow shows the coarse primary boride.

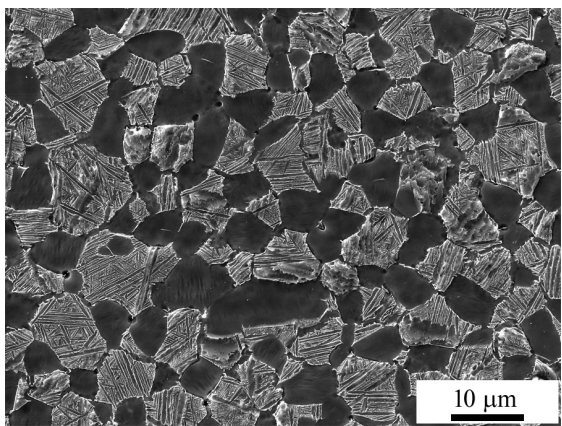

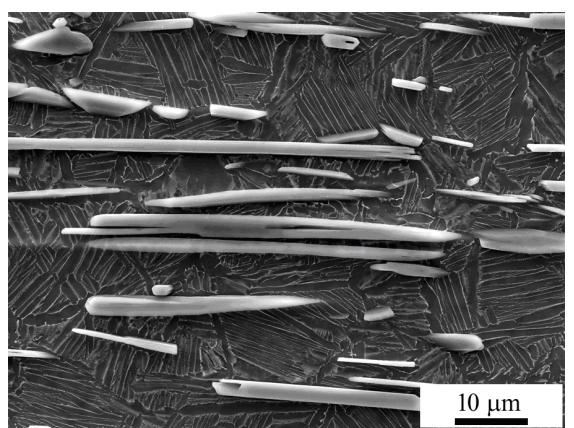

$\mathrm{b}$

Рис. 2. Микроструктура (а) ВТ25У и (b) ВТ25У-1,5В после ковки и термической обработки (РЭМ, SE). Направление вытяжки деформированной заготовки - горизонтальное.

Fig. 2. Microstructures of (a) VT25U and (b) VT25U-1,5B after hot forging and heat treatment (SEM, SE). The workpiece drawing direction is horizontal.

На рис. 3 представлены прямые полюсные фигуры $\{010\} \mathrm{TiB}$ и $\{11-20\} \alpha-\mathrm{Ti}$, полученные для композита ВТ25У-1,5В после деформационной и термической обработки. Измерения показали, что направление [010] TiВ-волокон примерно параллельно направлению вытяжки деформированной заготовки, максимальная относительная интенсивность достигает 49. Известно [17], что продольное направление ТіВ-волокон совпадает с направлением $[010]_{\text {тів }}$ кристаллической решетки, т.е. волокна боридов после деформации вытянулись перпендикулярно двум направлениям ковки вдоль направления вытяжки заготовки. Текстура в $\alpha$-фазе оказалась довольно размытой, никакого определенного направления, имеющего существенную относительную интенсивность и ориентированного параллельно направлению вытяжки заготовки, не выявлено (рис. 3).

Согласно [12], ориентационное соотношение между TiB-волокнами и титановой матрицей: $[11-20]_{\mathrm{Ti}} \|[010]_{\mathrm{TiB}}$, $(0001)_{\mathrm{Ti}} \|(001)_{\text {тів }}$ и $(1-100)_{\mathrm{Ti}} \|(100)_{\mathrm{TiB}}$. Тот факт, что в $\alpha$-фазе направление $<11-20>$ не ориентировано параллельно направлению вытяжки деформированной заготовки указывает на то, что условия деформационной обработки оказались для этого недостаточно благоприятными. Таким образом, деформационная обработка не привела к формированию острой $[11-20]_{\text {Ti }}$ текстуры в $\alpha$-фазе, что, по-видимому, препятствовало формированию и более острой текстуры ТіВ-волокон. Следует от- метить, что в случае композита на основе ВТ8 подобная деформационная обработка привела к формированию намного более острой текстуры как волокон, так и $\alpha$-фазы [13]. Тем не менее, можно говорить о формировании преимущественно ориентированных ТіВ-волокон после ковки, причем благодаря деформации в $\beta$ фазовой области большинство боридов не раздробилось и сохранило высокое отношении длины к поперечному размеру, что важно для достижения максимального упрочняющего эффекта.

\section{3. Механические свойства при растяжении}

На рис. 4 представлены механические свойства при растяжении, полученные для сплава ВТ25У и композита ВТ25У-1,5В в состояниях, полученных после деформационной и термической обработки. Присутствие преимущественно ориентированных ТіВ-волокон привело к заметному упрочнению, как при комнатной, так и повышенных температурах при сохранении приемлемых значений пластичности. Если принять величину предела текучести матрицы и сплава ВТ25У примерно одинаковой, то прирост предела текучести в диапазоне температур испытания $20-700^{\circ} \mathrm{C}$ благодаря присутствию 8 об. \% ТіВ-волокон составляет 22 - $50 \%$ при сохранении пластичности композиционного материала при комнатной температуре на уровне $\delta=3 \%$ (рис. 4). Предел проч- 


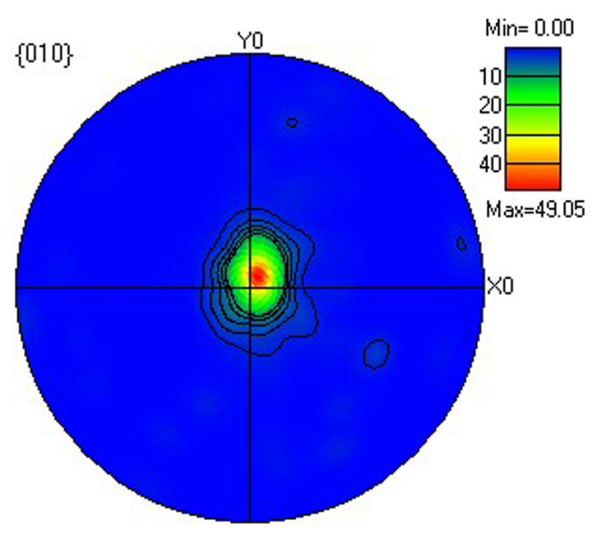

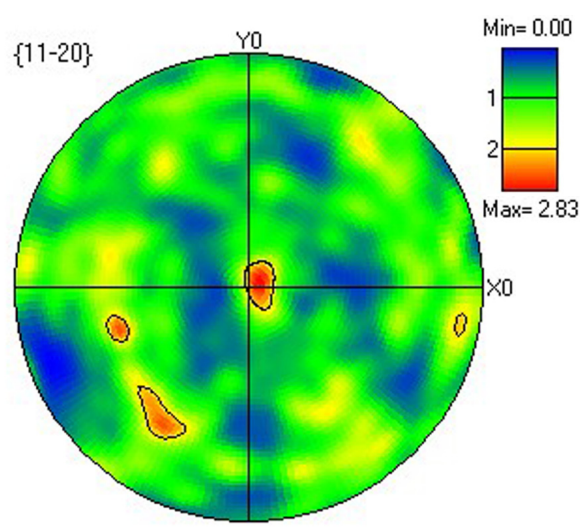

$\mathrm{b}$

Рис. 3. Прямые полюсные фигуры (a) $\{010\} \mathrm{TiB}$ и (b) $\{11-20\} \alpha$-Ті, полученные для композита ВТ25У-1,5B после деформационной и термической обработки.

Fig. 3. Pole figures of (a) $\{010\} \mathrm{TiB}$ and (b) $\{11-20\} \alpha$-Ti obtained for the VT25U-1.5B composite subjected to forging followed by heat treatment.
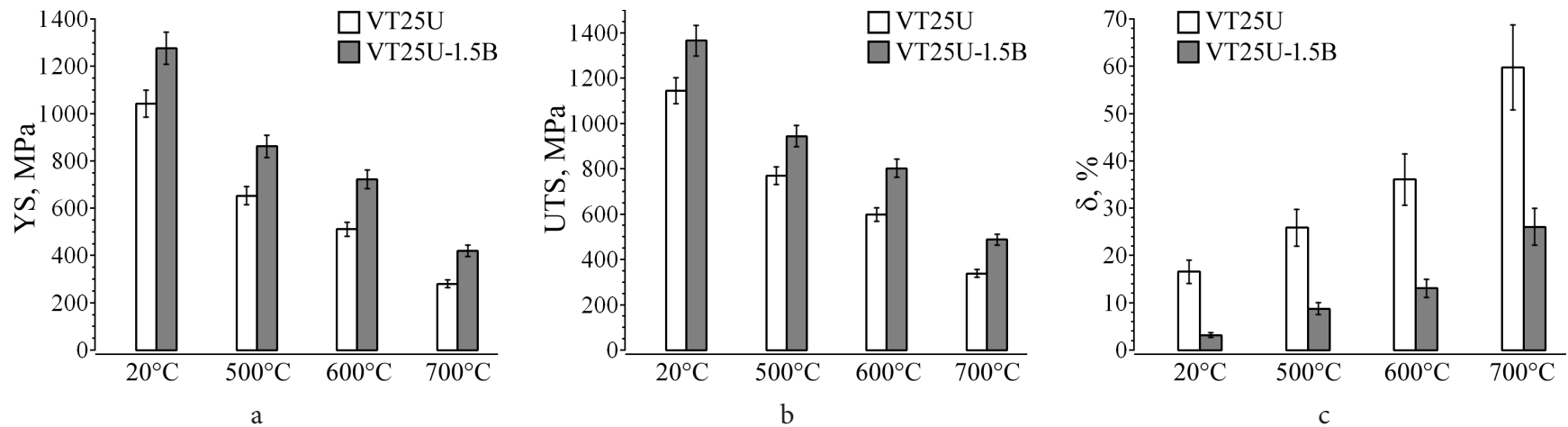

Рис. 4. Температурные зависимости, полученные для сплава ВТ25У и композита ВТ25У-1,5В после деформационной и термической обработки: (а) предела текучести $\sigma_{0,2}$, (b) предела прочности $\sigma_{\mathrm{B}}$, (c) относительного удлинения $\delta$.

Fig. 4. Temperature dependencies of (a) yield strength, $\sigma_{02}$, (b) ultimate tensile strength, $\sigma_{\mathrm{UTS}}$, and (c) elongation to rupture, $\delta$, obtained for the VT25U alloy and the VT25U-1.5B composite.

ности композита при комнатной температуре составил $\sigma_{\mathrm{B}}=1364 \mathrm{MПа,} \mathrm{при} T=500^{\circ} \mathrm{C}-\sigma_{\mathrm{B}}=943 \mathrm{MПа}$. По удельной прочности при $T=500-700^{\circ} \mathrm{C}$ композит ВТ25У-1,5B существенно превосходит не только ВТ25У, но и все традиционные титановые сплавы с рабочей температурой $500-600^{\circ} \mathrm{C}$, такие как ВТ9, ВТ25, ВТ38, ВТ18У, ВТ41 и др. [2].

Интересно отметить, что удельный вклад ТіВ-волокон в упрочнение с повышением температуры испытания возрастает от $22 \%$ при комнатной температуре до $41-50 \%$ при $T=600$ и $700^{\circ} \mathrm{C}$, что указывает на сохранение высокой адгезионной прочности границ между титановой матрицей и ТiB-волокнами с повышением температуры деформации. Величина упрочняющего эффекта за счет присутствия ТіВ-волокон примерно согласуется с известной моделью сдвигового запаздывания для коротковолокнистых композиционных материалов $[10,13,16,18]$. При этом рост удельного вклада TiB-волокон в упрочнение с повышением температуры деформации, по-видимому, связан с уменьшением сдвигового запаздывания и увеличением удельной несущей способности упрочняющих волокон с повышением температуры.

\section{4. Испьтания на ползучесть}

Испытания на ползучесть показали, что композиционный материал с предпочтительно ориентированными ТіВ-волокнами демонстрирует существенно более высокое сопротивление ползучести при $T=550$ и $600^{\circ} \mathrm{C}$, чем матричный сплав (рис. 5). По-видимому, положительный эффект от присутствия боридов мог бы быть выше в случае более острой текстуры ТіВ-волокон. Отметим, что для матрицы из сплава ВТ8 присутствие 8 об. \% боридов привело к смещению кривых ползучести к высоким температурам на $50^{\circ} \mathrm{C}$ [13].

\section{5. Разрушение}

На рис. 6 представлена поверхность образцов композита вблизи зоны разрушения после испытаний при разных температурах. Видно, что при всех температурах испытания происходило интенсивное дробление ТіВволокон. Учитывая на порядок более высокую прочность моноборида титана по сравнению с титановой матрицей (Табл. 1), это свидетельствует о том, что бориды очень эффективно принимают на себя нагрузку, 
передаваемую от матрицы. Важно отметить, что отслоение волокон от матрицы и образование несплошностей между матрицей и волокнами при всех температурах испытания наблюдается только локально вблизи мест дробления боридов, в то время как этого не происходит вдоль длины нераздробленной части боридов. Несмотря на относительно большие достигнутые удлинения при $T=600$ и $700^{\circ} \mathrm{C}(\delta=13$ и $26 \%)$ и интенсивное дробление боридов, значительного разрушения границ матрица-упрочнитель не наблюдается. Это согласуется с данными работ $[6,15]$, в которых отслоение ТіВ-волокон от матрицы наблюдали только при $T>700^{\circ} \mathrm{C}$. Таким образом, высокая прочность границ между титановой матрицей и ТіВ-волокнами сохраняется с повышением температуры испытания до $T=700^{\circ} \mathrm{C}$, что коррелирует с сохранением значительного вклада боридов в упрочнение при повышенных температурах. Безусловно, это важный довод в пользу применения моноборида титана в качестве упрочнителя титановой матрицы.

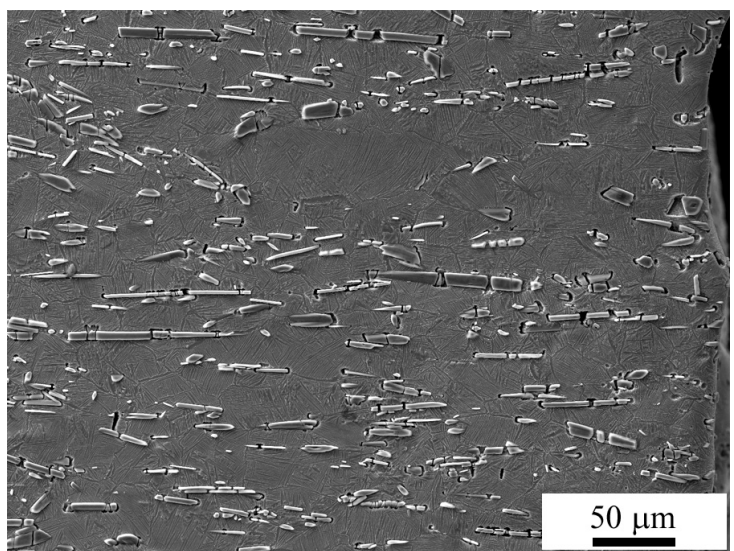

a

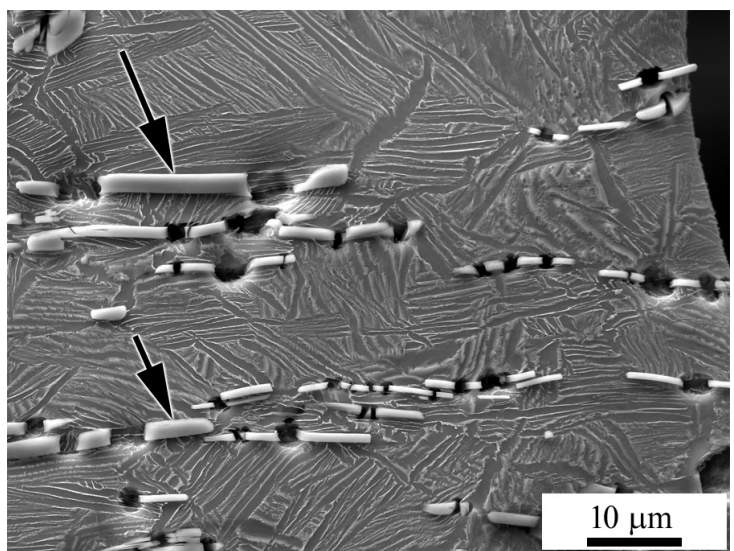

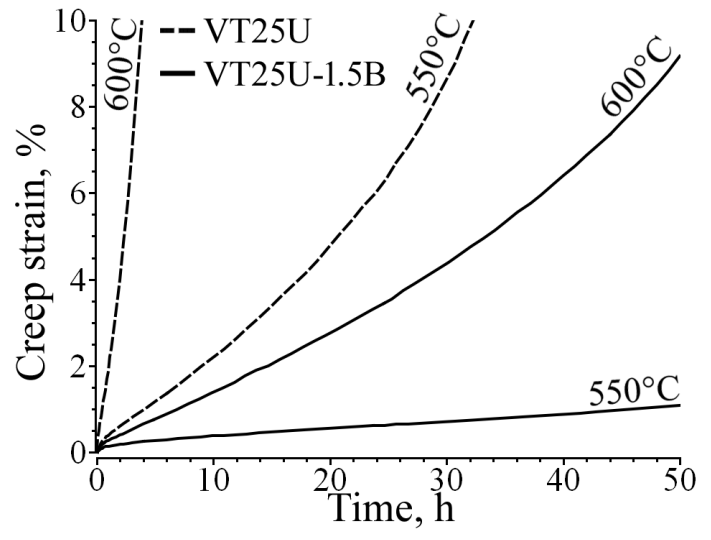

Рис. 5. Кривые ползучести, полученные для образцов сплава ВТ25У и композита ВТ25У-1,5В при $T=550^{\circ} \mathrm{C}(P=400$ МПа $)$ и $T=600^{\circ} \mathrm{C}(P=300 \mathrm{MПа})$.

Fig. 5. Creep curves obtained for the VT25U alloy and the VT25U-1.5B composite at $T=550^{\circ} \mathrm{C}(P=400 \mathrm{MPa})$ and $T=600^{\circ} \mathrm{C}$ $(P=300 \mathrm{MPa})$.
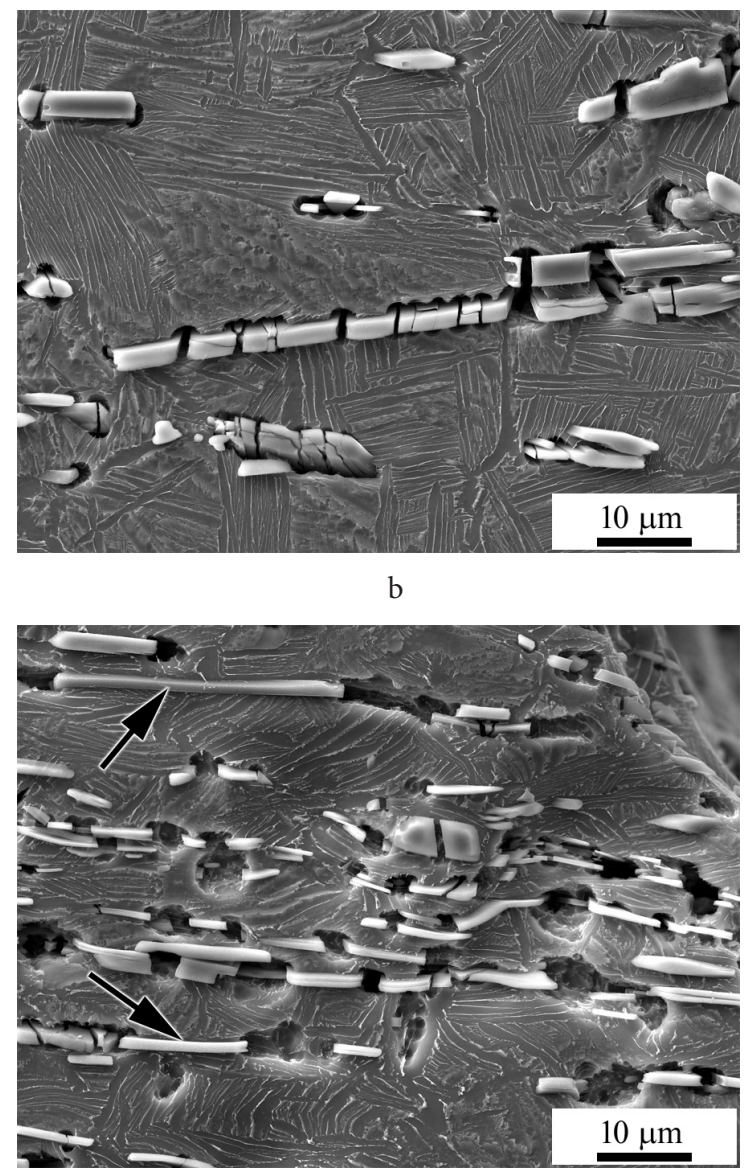

Рис. 6. Поверхность образцов композиционного материала ВТ25У-1,5B после испытаний на растяжение: (a, b) $T=20^{\circ} \mathrm{C}(\delta=3 \%),(\mathrm{c})$ $T=600^{\circ} \mathrm{C}(\delta=13 \%),(\mathrm{d}) \mathrm{T}=700^{\circ} \mathrm{C}(\delta=26 \%)(\mathrm{PЭM}, \mathrm{SE})$. Отслоение боридов от матрицы и образование несплошностей происходит локально вблизи мест дробления боридов. В качестве примера, стрелки указывают на нераздробленные части боридов, вдоль которых отслоения и образования несплош-ностей не наблюдается. Изображения получены вблизи зоны разрушения, ось растяжения - горизонтальная.

Fig. 6. The flat surfaces of specimens of the VT25U-1,5B composite tensile tested at (a, b) $T=20^{\circ} \mathrm{C}(\delta=3 \%),(\mathrm{c}) \mathrm{T}=600^{\circ} \mathrm{C}(\delta=13 \%),(\mathrm{d})$ $T=700^{\circ} \mathrm{C}(\delta=26 \%)$. Interfacial debonding and formation of discontinuities between the matrix and the borides occur locally near breaking of the borides. By way of illustration, arrows show unbroken boride fragments, along of which interfacial debonding and formation of discontinuities are not observed. The pictures were obtained near the fracture zones, the tensile axis is horizontal. 
Изучение поверхности разрушения образцов композита ВТ25У-1,5В после испытаний при разных температурах показало, что характер разрушения качественно не меняется с повышением температуры деформации, при этом разрушение композита начинается с разрушения волокон с последующим вязким разрушением матрицы. Неблагоприятно ориентированные бориды способствуют разрушению сколом, что снижает в целом эффективность упрочнения от присутствия борида.

Выполненное исследование показало эффективность армирования титановых сплавов моноборидом титана и литья, как доступного и дешевого in situ способа изготовления композитов на основе Ti/TiB. Композит ВТ25У/ТiВ с содержанием коротких ТіВ-волокон 8 об. \% был получен обычным литьем с последующей деформационной обработкой, обеспечившей эффективную переориентацию боридов в одном направлении. Важным достоинством таких композитов является возможность осуществления термической обработки в $\beta$ фазовой области, что не вызывает быстрого роста $\beta$-зерен благодаря присутствию боридов и способствует достижению наиболее высокой жаропрочности за счет формирования полностью $\beta$ превращенной пластинчатой структуры. Высокая адгезионная прочность границ между титановой матрицей и ТіВ-волокнами сохраняется с повышением температуры испытания, что важно для создания жаропрочных композиционных материалов на основе $\mathrm{Ti} / \mathrm{TiB}$, способных работать при $T \geq 600^{\circ} \mathrm{C}$. Дальнейшие исследования представляют интерес в направлении подбора наиболее жаропрочной матрицы и эффективного способа управления текстурой ТiB-волокон, сохраняющего высокую адгезионную прочность границ между матрицей и упрочняющими волокнами при $T \geq 600^{\circ} \mathrm{C}$.

\section{4. Заключение}

В работе изучали новый композиционный материал на основе ВТ25У/ТiВ, изготовленный литьем и подвергнутый деформационной обработке для формирования преимущественно ориентированных ТiB-волокон. По результатам могут быть сделаны следующие выводы:

1. Для матрицы из ВТ25У оптимальное количество вводимого бора составляет 1,5 вес. \%, что соответствует 8 об. \% ТіВ-волокон. Введение большего количества бора приводит к формированию грубых первичных боридов и неоднородному распределению боридов.

2. Деформационная обработка композиционного материала ВТ25У/8 об. \% ТіВ, включающая в себя изотермическую ковку в двух направлениях при температуре $\beta$ фазовой области, эффективна для достижения преимущественной ориентации ТіВ-волокон. Дальнейшее повышение остроты текстуры ТіВ-волокон возможно за счет увеличения деформации.

3. В композите ВТ25У / 8 об. \% ТіВ после деформационной итермическойобработкиобеспечивается существенное (на $22-50 \%$ ) упрочнение при $T=20-700^{\circ} \mathrm{C}$ и значительное повышение сопротивления ползучести при температурах $T=550-600^{\circ} \mathrm{C}$ по сравнению с матричным сплавом при сохранении приемлемой пла- стичности ( $\delta=3 \%$ при комнатной температуре). Упрочнение композита обусловлено высокой адгезионной прочностью границ между матрицей и ТіВ-волокнами, сохраняющейся при повышенных температурах. Показано, что разрушение композита ВТ25У/ТiВ начинается с ТiB-волокон с последующим вязким разрушением матрицы.

Благодарность/Aknowledgements. Работа выполнялась в рамках программы фундаментальных исследований Российской академии наук, регистраиионный номер - АААА-A17-117041310215-4, а также при поддержке Российского фонда фундаментальных исследований, грант РФФИ № 16-33-00723 мол_а.

\section{Литература/References}

1. Group of authors, ed. by Ju. S. Karabasov. New Materials. Moscow. MISiS (2002) 736 p. (in Russian) [Новые материалы. Науч. ред. Ю. С. Карабасов. Москва. МИСИС (2002) 736 c.].

2. A. A. Il'in, B.A. Kolachev, I.S. Pol'kin. Titanium alloys. M. VILS-MATI (2009) 519 p. (in Russian) [А. А. Ильин, Б.А. Колачев, И.С. Полькин. Титановые сплавы. М. ВИЛС-МАТИ. (2009) 519 с.].

3. K. S. R. Chandran, K. B. Panda, S. S. Sahay. JOM. 56 (5), $42-48$ (2004).

4. T.M. T. Godfrey, P.S. Goodwin, C.M. Ward-Close. Adv. Eng. Mater. 2 (3), 85 - 92 (2000).

5. D. Hill, R. Banerjee, D. Huber, J. Tikey, H. L. Fraser. Scr. Mater. 52, 387 - 392 (2005).

6. C. J. Zhang, F.T. Kong, L.J. Xu, E.T. Zhao, S.L. Xiao, Y. Y. Chen, N. J. Deng, W. Ge, G. J. Xu. Mater. Sci. Eng. A. 556, 962 - 969 (2012).

7. I. Sen, L. Maheshwari, S. Tamirisakandala, D. B. Miracle, U. Ramamurty. Mater. Sci. Eng. A. 518, 162 - 155 (2009).

8. O.M. Ivasishin, R. V. Teliovych, V.G. Ivanchenko, S. Tamirisakandala, D. B. Miracle. Metall. Mater. Trans. A. $39,402-416$ (2008).

9. C. Zhang, F. Kong, Sh. Xiao, H. Niu, L. Xu, Y. Chen. Mater. Des. 36, 505 - 510 (2012).

10. M. J. Koo, J.S. Park, M.K. Park, T.K. Kyung, and S. H. Hong. Scr. Mater. 66, 487 - 490 (2012).

11. B. Wang, L. J. Huang, L. Geng. Mater. Sci. Eng. A. 558, $663-667$ (2012).

12. X. Guo, L. Wang, M. Wang, J. Qin, D. Zhang, W.Lu. Acta Mater. 60, 2656-2667 (2012).

13. V.M. Imayev, R.A. Gaisin, R.M. Imayev. Mater. Sci. Eng. A. 641, $71-83$ (2015).

14. B. Wang, L. J. Huang, H. T. Hu, B. X. Liu, L. Geng. Mater. Character. 103, 140-149 (2015).

15. C. Zhang, X. Li, S. Zhang, L. Chai, Z. Chen, F. Kong, Y. Chen. Mater. Sci. Eng. A. 684, 645-651 (2017).

16. F. Ma, S. Lu, P. Liu, W. Li, X. Liu, X. Chen, K. Zhang, D. Pan, W. Lu, D. Zhang. J. Alloy. Compd. 695, 1515-1522 (2017).

17. H. B. Feng, Y. Zhou, D. C. Jia, Q. C. Meng, J. C. Rao. Cryst. Growth Des. 6, 1626 - 1630 (2006).

18. H. Fukuda, T.W. Chou. J. Mater. Sci. 16, 1088-1096 (1981). 